\title{
Defecto vertebral múltiple con otras anomalías acompañantes
}

\author{
E. Gar cía Barrecheguren, M. Alfonso Olmos y J.L. Beguiristáin Gúrpide
}

Departamento de Cirugía Ortopédica y Traumatología. Clínica Universitaria de Navarra. Pamplona.

(An Esp Pediatr 2001; 54: 409-410)

\section{Caso CLínico}

Niño de 5 años y medio, nacido por parto espontáneo con presentación podálica, a las 40 semanas, con un peso de $2.700 \mathrm{~g}$ y $47 \mathrm{~cm}$ de longitud. Incontinencia urinaria y fecal (distonía anal). Criptor quidia bilateral (forma abdominal) . Otitis izquier da de repetición. No existían alergias medicamentosas. El paciente se desplaza arrastrándose con apoyo de las extremidades superior es y rodillas (fig. 1).

En la exploración física se doserva cifosis dorsal angular con gran prominencia ósea central.

Nalgas estrechas y aplanadas con acortamiento del surco interglúteo y formación de hoyuelos lateralmente a la hendidura.

Rodillas en flexo. Derecha, flexión, 115, extensión, -105 \% izquier da, flexión, $105^{\circ}$, extensión, $-90^{\circ}$. Membrana

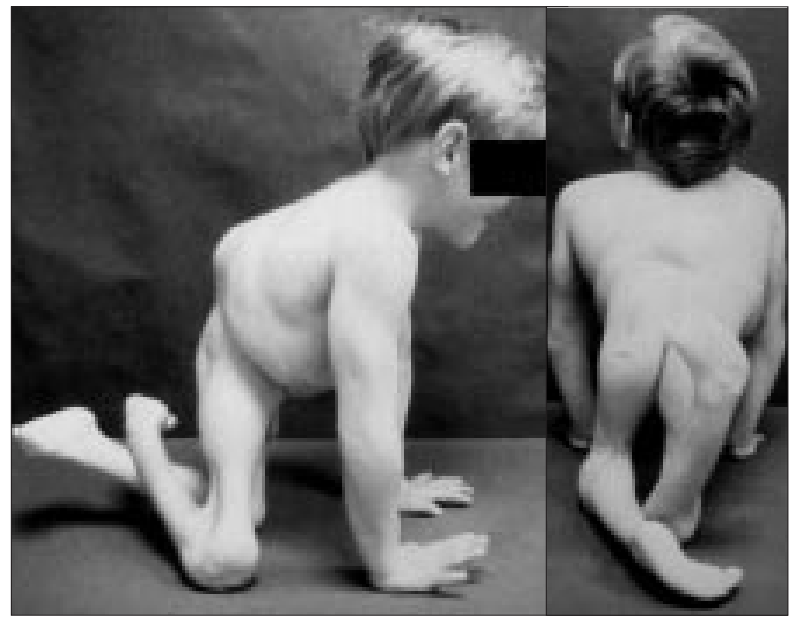

Figura 1. El mor fotipo característico de esta enfermedad ha llevado a denominar a estos pacientes "niños Buda". poplítea bilateral. Caderas: derecha rígida en extensión, izquier da flexœextensión, $15^{\circ}$ pasiva, aboucción $15^{\circ}$ bilateral. Pies equinovaros rígidos debajo de las nalgas. Sensibilidad táctil pr ofunda conservada. Cicatrices en cara medial de ambos muslos y rodillas (varios intentos de corrección quirúrgica del flexo de rodillas) .

La radiografía de columna anter oposterior reveló tórax ancho, costillas paralelas, anomalía del desarrollo de las vértebras de la por ción torácica inferior, lumbar y ausencia total de sacro. Displasia acetabular bilateral con luxación alta de caderas (fig. 2).

consultó por posibilidades de tratamiento para conseguir una mejoría funcional.

\section{Pregunta}

¿Cuál es su diagnóstico?

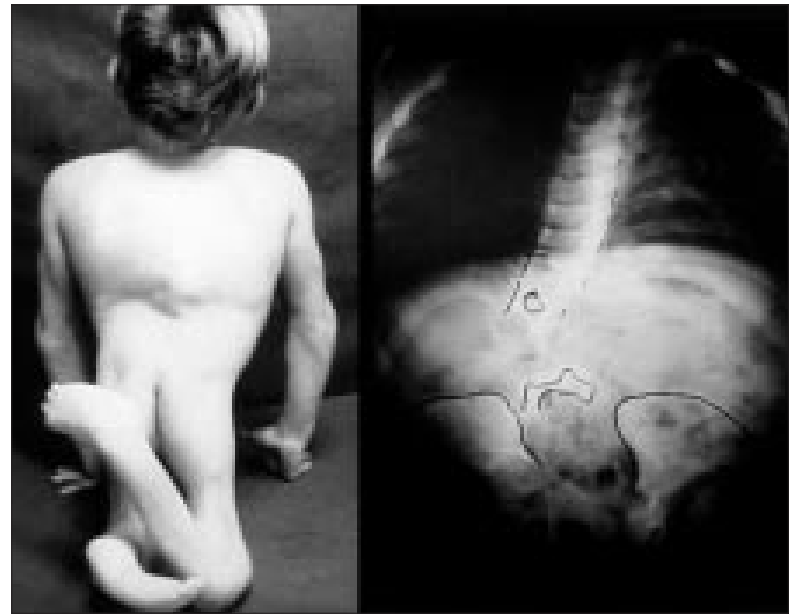

Figura 2. Desaparición de varios segmentos vertebrales. En el dorso se doserva una prominencia ósea que corresponde al último segmento vertebral presente.

Correspondencia: Dra. E. García Barrecheguren.

Clínica Universitaria de Navarra.

Avda. Pío XII, s/n. 31008 Pamplona.

Correo electrónico: egar ciab@unav.es

Recibido en junio de 2000.

Aceptado para su publicación en septiembre de 2000. 


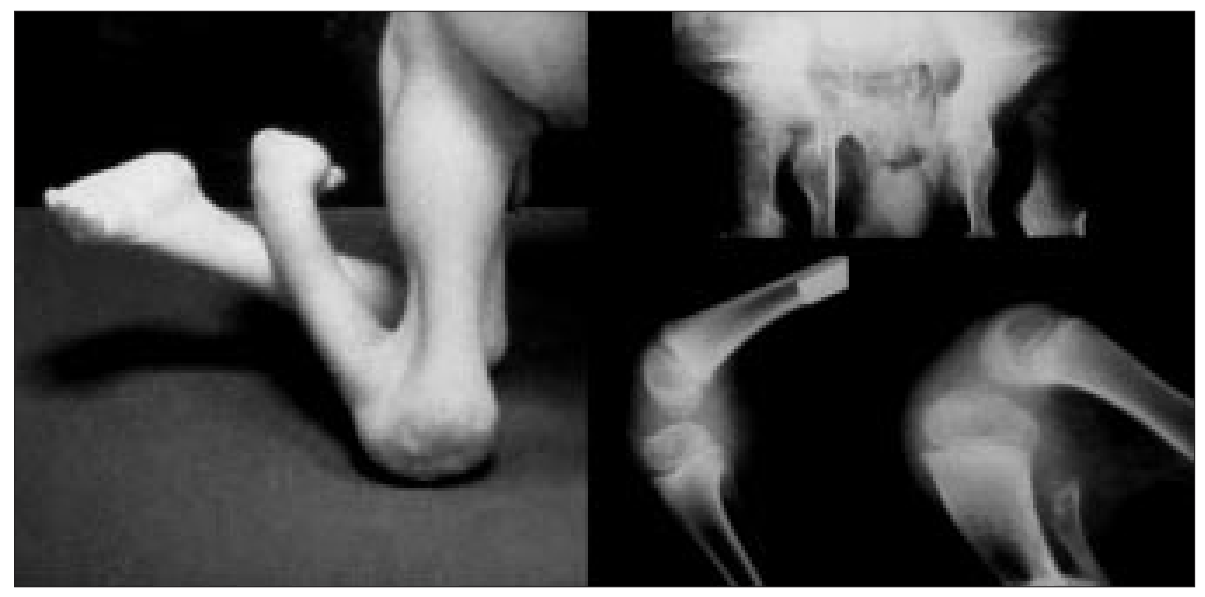

Figura 3. Obsérvese el importante flexo de rodillas con la presencia de membrana poplítea. Luxación teratológica de caderas. Pies zambos rígidos bajo los glúteos.

\section{SÍNDROME DE REGRESIÓN CAUDAL: AGENESIA DE SACRO}

Las malformaciones congénitas de la cintura pélvica pueden producirse en el contexto de una enfermedad generalizada del esqueleto (p. ej., acondroplasia, displasia cleidocraneal, etc.) o en el marco de una malformación locorregional. Estas últimas se integran en el grupo de las disostosis, lo que supone de forma constante la asociación de anomalías viscerales, urológicas o neur ológicas, por lo que se conocen bajo el nombre de síndrome de regresión caudal. Este síndrome engloba desde una aplasia coccígea asintomática hasta una agenesia sacra, lumbar e incluso torácica a distintos niveles con graves déficit neur ológicos; pero lo más frecuente es la ausencia total o parcial sacra, por lo que el término de agenesia sacra, agenesia caudal o síndr ome de regresión caudal se utilizan como sinónimos ${ }^{1}$.

Existen diversas clasificaciones de las agenesias sacras. La más conocida es la de Renshaw ${ }^{2,3}$, en la actualidad modificada por Pang, según las características radiológicas de las malformaciones y su intensidad.

Puesto que la frecuencia de las malformaciones viscerales asociadas es muy similar con independencia de la gravedad de la alteración ósea, cremos útil la clasificación de Bollini y Jauve basada en la existencia y tipo de problemas ortopédicos ${ }^{1}$.

Grupo I. Agenesia sacra total con agenesia lumbar o toracolumbar de altura variable.

Problemas ortopédicos: flexo de cadera; flexo grave de rodilla con membrana poplítea; inestabilidad espinopélvica si existe cifosis.

Grupo II . Disgenesia de articulaciones sacroilíacas.
Problemas ortopédicos: escoliosis angular variable; traslación del tronco.

Grupo III. Agenesia sacra parcial con articulaciones sacroilíacas estables (S2).

Problemas ortopédicos: posibilidad de displasia de caderas; deformidad unilateral de pie.

Este caso se corresponde con una agenesia sacra total con agenesia lumbar múltiple (grupo I), con luxación teratológica de caderas, rodillas flexas irreducibles, con membrana poplítea y pies zambos irreducibles, además de una cifosis funcional (fig. 3).

El polimor fismo de esta enfermedad supone un enfoque multidisciplinario incluyendo como gesto terapéutico y supone lograr la bipedestación mediante aparatos ortopédicos y así una mejor integración social la desarticulación de ambas rodillas y la estabilización de la columa dorsolumbar a ilíacos ${ }^{1,4,5}$.

\section{BibliografíA}

1. Bollini G, Jouve Jl, Cottalor da J. Malformations congénitales de la ceinture pelvienne. Encycl Méd Chir (Elsvier, Paris France), Appareil locomoteur 1994; 15: 225-310.

2. Méndez MJ, Cid E, Rodrigo E. Nota clínica: síndrome de regresión caudal. An Esp Pediatr 1996; 44: 405-408.

3. Ruiz JA,Molina MI, Moros M et al. Nota clínica:Agenesia parcial de sacro y microcefalia:Una asociación poco frecuente. An Esp Pediatr 1997; 46: 607-610.

4. Natarajan MC. Surgical treatment of nonprogressive neur ological deficits in diildren with sacral agenesis. Neur osurg 1996; 38: $1133-1138$.

5. Van Buskirk CS, Rittenbusch JF. Natural history of distal spinal agenesis. J Pediatr Orthop 1997; 6: 146-152. 